\title{
Sound characterization of the European lobster Homarus gammarus in tanks
}

\author{
Youenn Jézéquel ${ }^{1, *}$, Julien Bonnel ${ }^{2}$, Jennifer Coston-Guarini ${ }^{1}$, Jean-Marc Guarini ${ }^{3}$, \\ Laurent Chauvaud ${ }^{1}$
}

\author{
${ }^{1}$ Laboratoire des Sciences de l'Environnement Marin, UBO, CNRS, IRD, Ifremer, LIA BeBEST, UMR 6539, \\ rue Dumont D'Urville, 29280 Plouzané, France \\ ${ }^{2}$ Woods Hole Oceanographic Institution, Woods Hole, Massachusetts 02543, USA \\ ${ }^{3}$ UPMC (Paris-6), UMR 8222 LECOB, Observatoire Océanologique de Banyuls sur Mer, 66650 Banyuls sur Mer, France
}

\begin{abstract}
Experiments in marine behavioural ecology rely heavily on observations made in tanks. However, when studying acoustic behaviours of marine animals in confined volumes, the effects of reverberation must be characterized, something that has been overlooked in parts of the marine ecology literature. In this study, we characterized reverberation in tanks using an artificial sound source and examined the implications for bioacoustic studies using sounds emitted by the European lobster Homarus gammarus during feeding and in response to stress. Broadband and transient sounds commonly produced by crustaceans were severely impacted by reverberation such that their spectral characteristics and pulse width durations could not be assessed. In contrast, lowfrequency sounds could be characterized in tanks, but not their source level. Based on these observations, we describe a simple methodology to identify which sound characteristics can be measured in tanks. When feeding, the lobsters produced broadband and transient sounds called 'rattles', similar to sounds reported for tropical spiny lobsters Palinurus longipes and $P$. argus. When stressed, $H$. gammarus vibrated its carapace, producing a low-frequency sound analogous to the 'buzzing' sound of the American lobster $H$. americanus. The potential role of species-specific sound is discussed; however, although our observations represent the first bioacoustic characterization of $H$. gammarus, additional behavioural studies are necessary to understand their ecological meaning.
\end{abstract}

KEY WORDS: European lobster · Passive acoustics · Tanks · Reverberation • Rattle • Buzzing sound • Spectral analysis

\footnotetext{
${ }^{*}$ Corresponding author: youenn.jezequel@univ-brest.fr
}

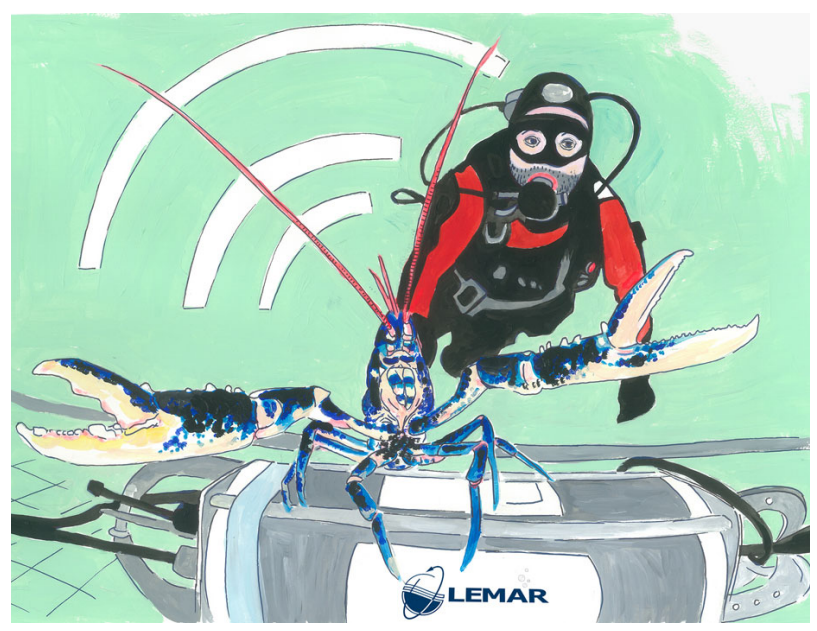

Bioacoustic experiment conducted in the Bay of Brest (Brittany, France) with European lobsters Homarus gammarus.

Painting:

Nathalie Bihan (redrawn from a photo by Erwan Amice)

\section{INTRODUCTION}

Bioacoustic studies of crustaceans have recently been receiving more attention in marine ecology (e.g. Edmonds et al. 2016). This has been driven partly by the commercial value, ubiquitous distribution and apparent ease of study of crustaceans compared with larger, highly mobile mammals. However, while the purpose of sounds emitted by whales and dolphins has been investigated for decades (Tyack \& Clark 2000), little is known about the ecological

() The authors 2018. Open Access under Creative Commons by Attribution Licence. Use, distribution and reproduction are unrestricted. Authors and original publication must be credited. 
roles of sounds made by crustaceans (Coquereau et al. 2016a,b, Edmonds et al. 2016). Recent studies have suggested that the sounds emitted by temperate marine decapods have properties suitable for in situ bioacoustic studies (e.g. Maja brachydactyla, Coquereau et al. 2016a).

Generally, marine crustaceans are known to produce a variety of sounds through different mechanisms, ranging from 'stridulation' in crabs (GuinotDumortier \& Dumortier 1960, Boon et al. 2009) to 'cavitation bubble collapse' in snapping shrimps (Knowlton \& Moulton 1963, Versluis et al. 2000), 'stick and slide friction' in palinurids (MeyerRochow \& Penrose 1976, Patek 2001) and 'carapace vibration' in nephropids and stomatopods (Henninger \& Watson 2005, Patek \& Caldwell 2006). Most reported sounds in the bioacoustic literature on crustaceans are broadband and transient ( $\mathrm{Au} \&$ Banks 1998, Patek et al. 2009, Coquereau et al. 2016a,b). Authors have suggested many hypotheses about the roles of these sounds, including antipredator defence in palinurids (Bouwma \& Herrnkind 2009, Buscaino et al. 2011) and intraspecific communication in paddle crabs (Buscaino et al. 2015). Some sounds are described as a consequence of identifiable activities, such as the 'rattles' emitted while feeding in palinurids (Moulton 1957, Meyer-Rochow \& Penrose 1976). A few crustacean species, including the American lobster Homarus americanus (Milne Edwards 1837), have been reported to emit low-frequency and narrowband sounds (Fish 1966, Henninger \& Watson 2005). When threatened or handled, the carapace of $H$. americanus vibrates and leads to a 'buzzing sound', due to the contraction of internal muscles located at the base of the second antenna (Fish 1966, Mendelson 1969, Henninger \& Watson 2005). The European lobster H. gammarus (Linnaeus 1758), which is closely related to the American lobster, has a similar anatomical morphology (Holthuis 1991), but no studies have yet reported on the sounds emitted by this species.

Most of the bioacoustic studies mentioned above have been performed in tanks because this permits the visual observations necessary to associate sounds with precise behaviours (Hazlett \& Winn 1962a,b, Meyer-Rochow \& Penrose 1974, 1976, Mulligan \& Fischer 1977, Patek \& Caldwell 2006, Patek \& Baio 2007, Patek et al. 2009, Buscaino et al. 2011, 2015, Coquereau et al. 2016a,b). However, the sound field in a tank is highly complex because of the interference caused by multiple reflections on the tank walls. Usually there are so many reflections that individual echoes cannot be resolved. This phenomenon is called reverberation and can be seen in data as the persistence of sound after its emission stops. It can prevent animal sounds from being properly characterized in tanks (Parvulescu 1964, 1967, Akamatsu et al. 2002). When reverberation occurs, standing waves may be generated by the superposition of reflected sound waves. Thus, what is recorded may correspond to the resonant frequencies of the standing wave because of its longer duration relative to the biological sound that was emitted (Akamatsu et al. 2002). The recorded spectrum becomes distorted and difficult to characterize. A large body of acoustic literature exists on the effects of reverberation when measuring broadband sounds (e.g. Pierce 1981, Schroeder 1996) but appears to have been largely overlooked within the bioacoustic community, although highlighted in the 1960s (Parvulescu 1964, 1967). However, the problem with reverbration has recently gained interest in this field in acoustic pressure (Akamatsu et al. 2002) and particle motion measurements (Duncan et al. 2016, Popper \& Hawkins 2018).

Nevertheless, bioacoustic studies in small tanks can still provide reliable information. Recently, Akamatsu et al. (2002) described for the first time the sound distortions produced in small tanks by combining empirical approaches with calculations from acoustic theory. This important, fundamental article focused on low-frequency and narrowband sounds emitted by fish. As reverberation is highly dependent on the frequency of interest with respect to the tank's resonant frequencies (which in turn depends on the tank's dimensions), the following applies: if the considered sound has a frequency on the order of, or higher than, the tank minimum resonant frequency, it will be affected by reverberation. The sound's duration is extended and its frequency content may be altered. On the contrary, if the considered sound has a frequency largely below the tank minimum resonant frequency, then the recorded sound is not impacted by reverberation (its duration and frequency content not being altered).

The purpose of this study was to characterize sounds produced by $H$. gammarus individuals during different activities and compare them with published information on $H$. americanus and other decapods. But, considering the limits of small tanks for bioacoustic studies, the first step was to determine the conditions under which reliable information on sounds emitted by this species can be collected. 


\section{MATERIALS AND METHODS}

All laboratory experiments were carried out at the Océanopolis public aquarium in Brest (Brittany, France).

The lobster Homarus gammarus (Crustacea, Malacostraca, Nephropidae) is a large (up to $6 \mathrm{~kg}$ ), mobile, nocturnal and commercially important crustacean in European coastal waters (Smith et al. 1998). Its life cycle is typical for a benthic crustacean, with a pelagic larval stage followed by benthic juvenile and adult stages and growth occurring through successive periods of molts (Cobb \& Wahle 1994, Sheehy et al. 1999, Agnalt et al. 2007).

\section{Animal collection, housing and care}

Seventeen $H$. gammarus individuals (10 females and 7 males) with a carapace length (CL) between 8.7 and $12 \mathrm{~cm}$ were collected through snorkeling in the Bay of Plougonvelin (Brittany, France) at depths between 1 and $10 \mathrm{~m}$ during January and February 2017. All individuals were transferred to a shaded, outdoor polyester circular tank (radius $=4 \mathrm{~m}$, effective height $=1.13 \mathrm{~m}$; seawater volume $=14.2 \mathrm{~m}^{3}$ ) for holding. The tank was continuously supplied with sand-filtered, UV-sterilized seawater pumped from the Bay of Brest. Temperature, salinity and animal conditions were controlled daily. During experiments, temperature varied between 9 and $12.5^{\circ} \mathrm{C}$ and salinity was between 32.8 and 34.6. Animals were fed with frozen squid, frozen mackerel and fresh mussels ad libitum and were kept under the natural photoperiod in this tank. Abundant sections of rigid PVC drainage pipes were provided as shelters. Lobsters were held together in the tank during the entire period of the study (around $4 \mathrm{mo}$, depending on the date of capture) when they were not being used for the experiments. No lobsters were harmed during the study. At the end of the study, all lobsters were transferred to the Océanopolis public aquarium.

\section{Experimental tanks}

Three types of rectangular tanks were used: 6 identical glass tanks $(0.60 \times 0.50 \times 0.35 \mathrm{~m}$, length $\times$ width $\times$ effective height; $0.105 \mathrm{~m}^{3}$ ), 1 plastic tank $\left(1.14 \times 0.92 \times 0.45 \mathrm{~m}^{0} 0.47 \mathrm{~m}^{3}\right)$ and 1 larger polyester tank $\left(2.10 \times 2.10 \times 0.53 \mathrm{~m}^{2} 2.34 \mathrm{~m}^{3}\right)$. During experiments, tanks were continuously supplied with the same seawater flow as for the holding tank. The 6 glass tanks and the plastic tank were in a slightly warmer room than the polyester tank, which resulted in somewhat warmer water conditions in the glass and plastic tanks $\left(13.9-14.5^{\circ} \mathrm{C}\right)$ than in the polyester tank $\left(9.0-12.5^{\circ} \mathrm{C}\right)$ during the study.

\section{Recordings}

Sounds were recorded using a pre-amplified hydrophone (HTI-92-WB, High Tech) with a sensitivity (SH) of $-155 \mathrm{~dB}$ re $1 \mathrm{~V} \mathrm{pPa}^{-1}$ and a flat response from 2 to $50 \mathrm{kHz}$. The hydrophone was connected to a compact autonomous recorder (EA-SDA14, RTSys) powered by battery to limit electronic self-noise. Recordings were made with a sampling frequency $\left(F_{\mathrm{s}}\right)$ of $156 \mathrm{kHz}$ at 32-bit resolution. Sounds, $S(t)$, were recorded in volts and then converted to pressure, $p(t)$ in $\mu \mathrm{Pa}$, in the time-domain $(t)$, using the following equation:

$$
p(t)=S(t) \times 10^{\frac{-G}{20}} \times D \times 10^{\frac{-\mathrm{SH}}{20}}
$$

where $G(\mathrm{~dB})$ is the recorder gain (here $G=14.7 \mathrm{~dB}$ ), $D$ is a constant for the dynamic response of the recorder ( $2 \mathrm{~V}$ for this model) and $\mathrm{SH}$ is the sensitivity of the hydrophone.

Finally, to associate a sound with a particular behavioural event, both visual observations and video recordings (GoPro® HERO3 camera) were made during experiments.

\section{Reverberation in the experimental tanks}

To quantify distortion in the 3 types of experimental tanks $\left(0.105 \mathrm{~m}^{3}\right.$ glass tank, $0.47 \mathrm{~m}^{3}$ plastic tank and $2.34 \mathrm{~m}^{3}$ polyester tank), an artificial sound was emitted into each one with an omnidirectional underwater speaker (AQUA 30, DNH, 8 Ohms, 20$20000 \mathrm{~Hz}$ ) associated with an amplifier (Plug and Play $12 \mathrm{~W}$ ) connected to a computer. During recordings in the tanks, the water pumps were switched off to reduce the background noise to a minimum. No animals were present in the tanks during these measurements. Sound was emitted for $2.5 \mathrm{~s}$, with an intensity spread equally over a wide band of frequencies (between $0 \mathrm{~Hz}$ and $24 \mathrm{kHz}$ ) to simulate white noise. The sound was emitted 5 times at different distances from the hydrophone, from 0.1 to $1.5 \mathrm{~m}$. Where peak frequencies appeared in the recorded white noise and had the same power spectrum level at different distances in a particular tank, these corresponded to the tank's resonant frequencies 
(Akamatsu et al. 2002). Recorded peaks were then compared to the theoretical resonant frequencies ( $f_{\text {rectangular, }} \mathrm{Hz}$ ) of a rectangular glass tank with the dimensions $L, W$ and $H$ (after Akamatsu et al. 2002):

$$
f_{\text {rectangular }}=\frac{C}{2} \sqrt{\left(\frac{l}{L}\right)^{2}+\left(\frac{m}{W}\right)^{2}+\left(\frac{n}{H}\right)^{2}}
$$

where $C$ is the sound velocity in the seawater (approximated at $1500 \mathrm{~m} \mathrm{~s}^{-1}$ in our case), $l, m$ and $n$ represent integers $(\geq 1)$, and the combination of these is called the 'mode number'. The minimum resonant frequency is then defined at mode $(1,1$, 1) for a particular tank dimension (Akamatsu et al. 2002).

\section{Experiments}

Sounds produced by individual lobsters during 2 different behaviours-feeding and response to stress-were recorded between March and May 2017 in the 8 tanks described above. During this period, 3 male lobsters molted within $1 \mathrm{wk}$ of each other. We took advantage of this to compare sounds emitted between intermolt (i.e. hard shell) and postmolt (i.e. soft shell) lobsters under the same conditions.

\section{Feeding}

Rattles were emitted when lobsters were feeding. Six lobsters (3 postmolt males, 3 intermolt males) were used in each tank type, and sound recordings were made with all 3 different food types: frozen squid, frozen mackerel and fresh mussels. Sound recordings started at least 10 min after the introduction of the hydrophone in the tanks, and food was introduced into the tank below the hydrophone. Recordings ended when all added food had been consumed; the sessions lasted from 10 min to several hours.

\section{Response to stress}

Buzzing sounds were provoked by handling organisms as described in the literature for American lobsters (Fish 1966, Henninger \& Watson 2005). All 17 lobsters were tested in each tank type. Individuals were gently lifted and maintained above the bottom of the tank for $20 \mathrm{~s}$ to $1 \mathrm{~min}$ in front of the hydrophone at distances between 10 and $20 \mathrm{~cm}$ for each recording.

\section{Conditions of tank recordings}

The hydrophone was suspended at the center of each tank, $20 \mathrm{~cm}$ above the bottom. Silicone mats $(0.5 \mathrm{~cm}$ thick) were placed on the bottom of the glasssided tanks to prevent sounds caused by the hard body parts of lobsters striking, or moving across, the glass. The 'daylight' conditions for experimental tanks were simulated using fluorescent light tubes above the tanks. The top of each tank was partially covered (25\% of the total surface) by a polystyrene sheet above, but not touching the water surface, to create a shaded zone.

During sound recordings, the water pumps were switched off to reduce the background noise to a minimum. The background noise in the experimental tanks was recorded prior to each recording experiment without lobsters. Spectra for the background noise were flat (around $40 \mathrm{~dB}$ re $1 \mathrm{\mu Pa}^{2} \mathrm{~Hz}^{-1}$ ), between $50 \mathrm{~Hz}$ and $75 \mathrm{kHz}$, with no typical peak frequencies compared to those that were present during experimental recordings with lobsters. At frequencies below $50 \mathrm{~Hz}$, peaks were present (up to $90 \mathrm{~dB}$ re $1 \mu \mathrm{Pa}^{2} \mathrm{~Hz}^{-1}$ ) and corresponded to instrumental selfnoise from the recorder. These were excluded from the biological sounds analysis.

Then, an individual lobster was carefully transferred to the experimental tank from the separate holding tank. Acclimatization lasted at least $2 \mathrm{~d}$ before recordings began, and animals continued to be fed ad libitum during this period. Recording sessions started after the individuals were considered acclimatized to the presence of the hydrophone in their tanks (i.e. when attacks on the hydrophone stopped). After recordings, individuals were returned to the separate holding tank, and sound files were archived for analysis.

\section{Sound analyses}

Acoustic characteristics of recorded sounds

Recordings of raw sounds (files in .wav format) and videos were analyzed simultaneously to associate particular sounds with behavioural events. Based on this file annotation, each sound type from the different recordings was extracted manually using Audacity $^{\circledR}$ (Version 2.1.1; Audacity Team 2015). Then, subsampled data from the converted recordings were analyzed between 1 and $78 \mathrm{kHz}$ for the identified rattle sequences and between 60 and $500 \mathrm{~Hz}$ for identified buzzing sound sequences. All sequences were 
processed using custom-made MATLAB (Version 9.1; $2016 b)$ scripts. The following characteristics were calculated.

The sound pressure level (SPL, in $\mathrm{dB}$ re $1 \mu \mathrm{Pa}$ ) was calculated for a time window equal to the length $(T)$ of the selected sound (Erbe 2010). For characterizing broadband and transient rattles, the peak-to-peak SPL, SPL

$$
\mathrm{SPL}_{\mathrm{pp}}=20 \log [\max (p(t))-\min (p(t))]
$$

where $\max (p(t))$ is the maximum value and $\min (p(t))$ the minimum value for the period, $T$. For continuous and narrowband buzzing sounds, the root-meansquare $\mathrm{SPL}, \mathrm{SPL}_{\mathrm{rms}}$, was calculated as:

$$
\mathrm{SPL}_{\mathrm{rms}}=20 \log \left(\sqrt{\frac{1}{T} \int_{T} p(t)^{2} d t}\right)
$$

The power spectral density was estimated by the periodogram, $\gamma\left(\right.$ in $\mathrm{dB}$ re $\left.1 \mu \mathrm{Pa}^{2} \mathrm{~Hz}^{-1}\right)$ :

$$
\gamma(f)=|P(f)|^{2}
$$

with $P(f)$ being the Fourier transformation at frequency $f$ of the time-domain signal $p(t)$ :

$$
P(f)=\int_{T} p(t) e^{-2 j \pi f} d t
$$

The peak frequency $\left(f_{p}\right.$, in Hz) is defined as the frequency at which the power spectral density is maximal. If the power spectral density contains several peaks, the frequency of the largest peak is called the first peak frequency.
Frequency bandwidth $(B, \mathrm{~Hz})$, was estimated as the measurement of the spread of the power spectral density (standard error) around the first peak frequency:

$$
B=\frac{\sqrt{\int(f-f p)^{2} \gamma(f) d t}}{\int \gamma(f) d f}
$$

Finally, in addition to rattles composed of trains of pulses (Fig. 1), we also calculated: (a) the duration of the entire sound $\left(T_{1}\right.$, in ms); (b) the pulse-to-pulse time interval $\left(T_{2}\right.$, in $\left.\mathrm{ms}\right)$; (c) the total number of pulses per train $(\mathrm{n})$; and $(\mathrm{d})$ the pulse rate $(R$, in $\mathrm{Hz})$, defined as the number of pulses per train (n) divided by the sound duration $\left(T_{1}\right)$. Time characteristics were calculated using the first attack of each pulse (Fig. 1).

\section{Statistical analysis}

Characteristics of postmolt and intermolt lobsters' buzzing sounds were tested to determine whether differences between groups were significant. Considering the small number of samples, and assuming that calculated variables for each individual can be assimilated to a random distribution, the non-parametric Mann-Whitney (MW) test was used to determine whether their probability distributions were identical (significance level, $\alpha=0.05$ ).
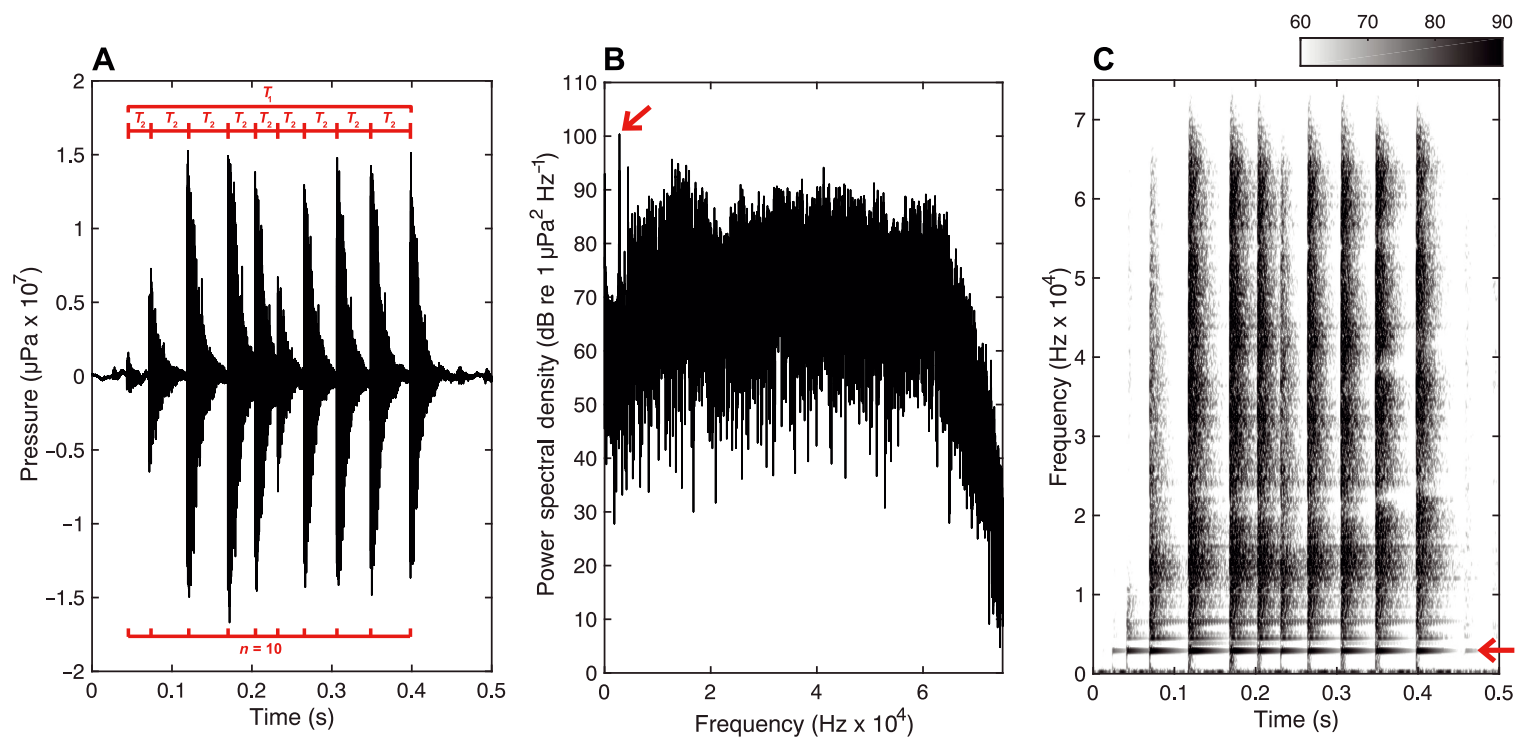

Fig. 1. Example of a typical rattle emitted in a $0.105 \mathrm{~m}^{3}$ glass tank by a European lobster (10.6 cm carapace length) plotted using 3 different time-series analyses. (A) Oscillogram, showing how the following characteristics were measured: the number of pulses per train $(n)$, the duration of the entire sound $\left(T_{1}\right)$ and the pulse-to-pulse time interval $\left(T_{2}\right)$. Time characteristics were calculated using the first attack of each pulse. (B) Acoustic spectrum (FFT size: 78126). (C) Spectrogram (FFT size: 1024; Hamming window: 501 points; $99 \%$ overlap). The red arrow indicates the first peak frequency $(2.8 \mathrm{kHz})$ and corresponded to the minimum resonant frequency computed for the $0.105 \mathrm{~m}^{3}$ tank $(2.9 \mathrm{kHz})$. The color scale is in dB re $1 \mu \mathrm{Pa}^{2} \mathrm{~Hz}^{-1}$ 


\section{RESULTS}

\section{Distortion of a known sound through tank reverberation}

From a white noise emitted, i.e. with the power spectral density being constant over a wide band of frequencies, signals recorded in different types of tanks were not flat and showed several peaks (Table 1). The first peak frequencies decreased as the dimensions of the tanks increased, ranging from $2.8 \mathrm{kHz}$ for a $0.105 \mathrm{~m}^{3}$ tank to $1.8 \mathrm{kHz}$ for the $2.34 \mathrm{~m}^{3}$ tank. These peaks occurred at frequency values matching the minimum theoretical resonant frequency calculated in the $0.105 \mathrm{~m}^{3}$ tank at 10 and $32 \mathrm{~cm}$ from the hydrophone $(2.8$ and $2.9 \mathrm{kHz}$, respectively). The same result was found for the $0.47 \mathrm{~m}^{3}$ tank at $10 \mathrm{~cm}$ from the hydrophone $(2 \mathrm{kHz})$, while peaks at $2.7 \mathrm{kHz}$ at 42 and $72 \mathrm{~cm}$ were also found, corresponding to another resonant frequency calculated with the mode $(2,2,1)$, even if the peak at $2 \mathrm{kHz}$ was still present. For the $2.34 \mathrm{~m}^{3}$ tank, the first frequency peak was $1.8 \mathrm{kHz}$ for the 3 distances from the hydrophone, and corresponded to a resonant frequency of mode (1, 1,2 ); a peak at $1.5 \mathrm{kHz}$ (the minimum resonant frequency of this tank) was also present. The power spectral density of the recorded white noise showed several other peak frequencies up to the minimum resonant frequency in each tank (until almost $20 \mathrm{kHz}$ ).
Fig. 1 shows a rattle emitted by an intermolt male lobster (10.6 cm in CL) during feeding experiments in a $0.105 \mathrm{~m}^{3}$ tank. The first peak frequency of this broadband sound was $2.8 \mathrm{kHz}$ (red arrow in Fig. 1), as also found for the recorded white noise in the same tank. It corresponded to the minimum resonant frequency of this tank, showing a net distortion of the sound.

Taking into account these results, we therefore calculated only time characteristics for the rattles, and SPL and spectral characteristics for buzzing sounds.

\section{Recordings made during feeding}

Rattles were defined as sound bursts consisting of a pulse train over a broadband spectrum (Fig. 1). A total of 168 rattles were recorded during feeding experiments with the 6 male lobsters (Table 2). These occurred when animals were feeding on all 3 types of foods. For almost 1 mo after molting, we did not record any rattles from the 3 soft lobsters, regardless of food type consumed. The time characteristics of these sounds were highly variable (Table 2): $T_{1}$ varied between 44 and $960 \mathrm{~ms}$ (mean $\pm \mathrm{SD}, 223.6 \pm$ $145.2 \mathrm{~ms}), T_{2}$ varied between 1 and $89 \mathrm{~ms}$ (65.1 \pm $13.8 \mathrm{~ms}), n$ varied between 3 and 41 pulses per train $(12 \pm 7.8)$ and $R$ varied between 6.11 and $200 \mathrm{~Hz}$ $(65.1 \pm 39.2 \mathrm{~Hz})$.

Table 1. Sound characteristics calculated for artificial white noise emitted at different distances from the source and in different tanks used for sound recording experiments. Results are presented as mean $( \pm \mathrm{SD})$. No animals were present during these recordings. $f_{\mathrm{p}}$ : peak frequency; $f_{\text {rectangular }}$ : theoretical resonant frequency

\begin{tabular}{|c|c|c|c|c|c|c|c|c|}
\hline \multirow{2}{*}{$\frac{\text { Tank size }\left(\mathrm{m}^{3}\right)}{\text { Distance from hydrophone }(\mathrm{cm})}$} & \multicolumn{2}{|c|}{$-0.105-$} & \multicolumn{3}{|c|}{-0.47} & \multicolumn{3}{|c|}{-2.34} \\
\hline & 10 & 32 & 10 & 42 & 72 & 10 & 80 & 150 \\
\hline$f_{\mathrm{p}}(\mathrm{kHz})$ & $2.8(0)$ & $2.8(0)$ & $2(0)$ & $2.7(0)$ & $2.7(0)$ & $1.8(0)$ & $1.8(0)$ & $1.8(0)$ \\
\hline$f_{\text {rectangular }}(\mathrm{kHz})$ & 2.9 & 2,9 & 2 & 2 & 2 & 1.5 & 1.5 & 1.5 \\
\hline
\end{tabular}

Table 2. Sound characteristics calculated in the European lobster rattles and buzzing sounds. The results are presented as means $( \pm \mathrm{SE})$. I: interference due to tank reverberation; NA: not applicable. $T_{1}$ : duration of the entire sound; $T_{2}$ : pulse-to-pulse time interval; $n$ : total number of pulses per train; $R$ : pulse rate; $\mathrm{SPL}_{\mathrm{pp}}$ : peak-to-peak sound pressure level; $\mathrm{SPL}_{\mathrm{rms}}$ : root-meansquare sound pressure level

\begin{tabular}{|c|c|c|c|c|c|c|c|c|c|}
\hline & $\begin{array}{l}\text { No. of } \\
\text { ind. }\end{array}$ & $\begin{array}{c}T_{1} \\
(\mathrm{~ms})\end{array}$ & $\begin{array}{c}T_{2} \\
(\mathrm{~ms})\end{array}$ & $n$ & $\begin{array}{c}R \\
(\mathrm{~Hz})\end{array}$ & $\begin{array}{c}\text { SPL (dB re } \\
1 \mu \mathrm{Pa})\end{array}$ & $\begin{array}{l}\text { First peak } \\
\text { frequency }\end{array}$ & $\begin{array}{l}\text { Second peak } \\
\text { frequency }\end{array}$ & $\begin{array}{l}\text { Band } \\
\text { width }\end{array}$ \\
\hline Rattles & 6 & $\begin{array}{c}223.6 \\
(145.2)\end{array}$ & $\begin{array}{c}12.4 \\
(13.8)\end{array}$ & $\begin{array}{c}12 \\
(7.8)\end{array}$ & $\begin{array}{c}65.1 \\
(39.2)\end{array}$ & $\begin{array}{l}\mathrm{SPL}_{\mathrm{pp}} \\
\quad \mathrm{I}\end{array}$ & $\begin{array}{c}\mathrm{kHz} \\
\mathrm{I}\end{array}$ & $\begin{array}{c}\mathrm{kHz} \\
\mathrm{I}\end{array}$ & $\begin{array}{c}\mathrm{kHz} \\
\mathrm{I}\end{array}$ \\
\hline Buzzing sounds & 7 & $\begin{array}{c}230 \\
(187.5)\end{array}$ & NA & NA & NA & $\begin{array}{c}\mathrm{SPL}_{\mathrm{rms}} \\
106.4 \\
(6.1)\end{array}$ & $\begin{array}{c}\mathrm{Hz} \\
100.9 \\
(19.6)\end{array}$ & $\begin{array}{c}\mathrm{Hz} \\
201.8 \\
(39.2)\end{array}$ & $\begin{array}{c}\mathrm{Hz} \\
56.1 \\
(22.5)\end{array}$ \\
\hline
\end{tabular}



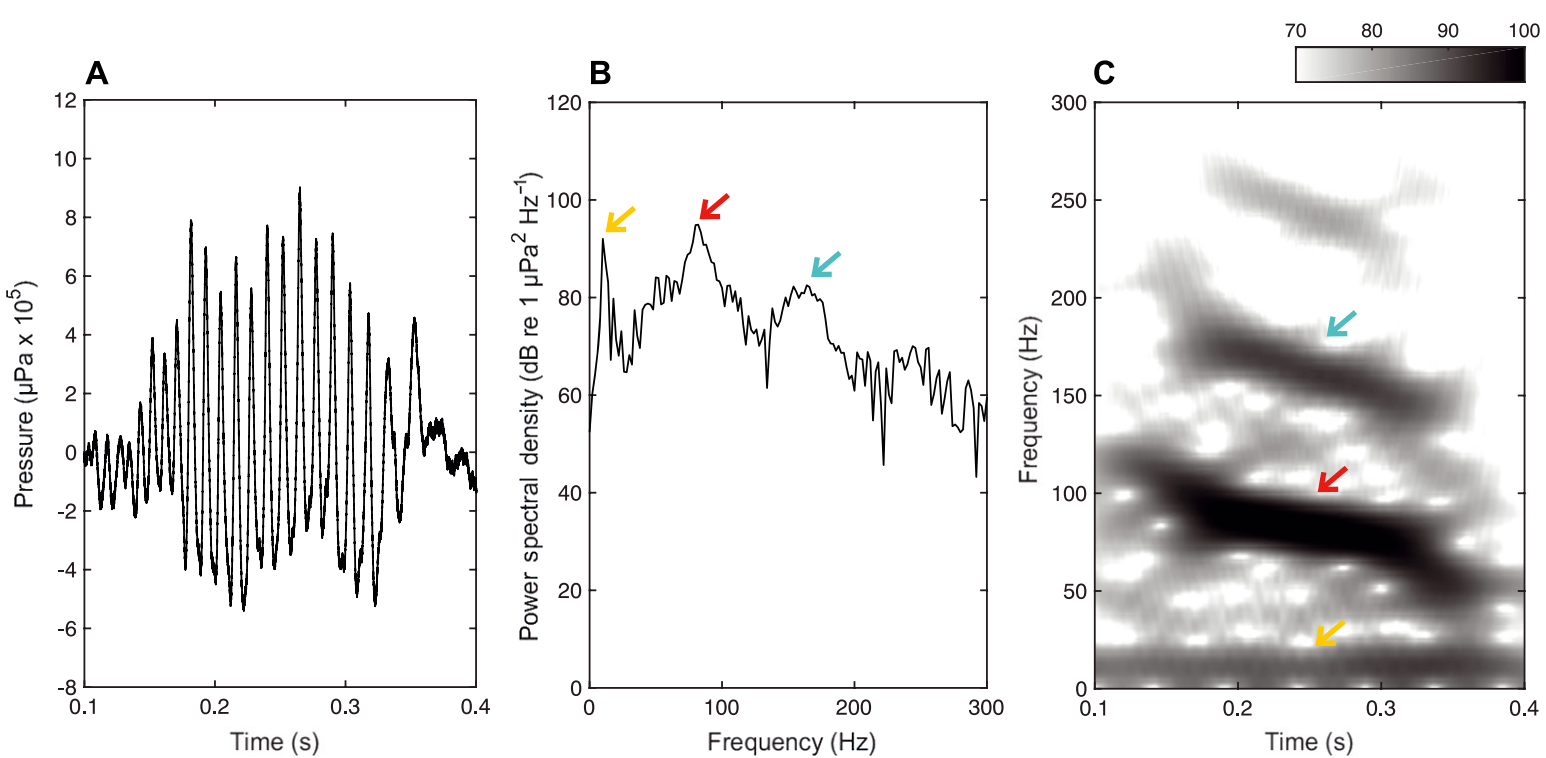

Fig. 2. Example of a buzzing sound produced in a $0.105 \mathrm{~m}^{3}$ glass tank by a 'soft' (postmolt) European lobster (9.5 $\mathrm{cm}$ carapace length) plotted using 3 different time-series analyses. (A) Oscillogram; (B) acoustic spectrum (FFT size: 46876); (C) spectrogram (FFT size: 2048; Hamming window: 501 points; $99 \%$ overlap). The yellow arrow indicates instrumental self-noise from the recorder, the red arrow indicates first peak frequency and the blue arrow indicates the second harmonic. The color scale is in $\mathrm{dB}$ re $1 \mu \mathrm{Pa}^{2} \mathrm{~Hz}^{-1}$

\section{Carapace vibration in a response to stress}

Buzzing sounds were defined as continuous sounds with a narrowband spectrum. A total of 189 buzzing sounds were recorded as a stress response by 7 individuals (1 intermolt female, 3 intermolt males and 3 postmolt males, ranging from 9 to $12 \mathrm{~cm}$ in CL) of the 17 lobsters tested (Table 2). These sounds occurred in association with carapace vibration (felt by hand) and were often associated with tail flips. Buzzing sounds were also recorded from the 2 most aggressive intermolt male lobsters (10.6 and $12 \mathrm{~cm}$ in CL) just before they attacked the hydrophone in the $0.105 \mathrm{~m}^{3}$ tanks during feeding experiments. These sounds had a mean first peak frequency of $100.9 \mathrm{~Hz}$ (range 66.6 to $152.6 \mathrm{~Hz}$ ) and were mainly $(92 \%$ of the analyzed recordings) accompanied by a second, strong harmonic with a mean frequency at second peak intensity of $201.8 \mathrm{~Hz}$ (range 123.2 to $305.2 \mathrm{~Hz}$ ). The number of harmonics detected varied from 2 to $>10$ for the most intense buzzing sounds. The buzzing sounds tended to decrease in frequency over time (Fig. 2), showing a net, mean frequency modulation of $56.1 \mathrm{~Hz}$ when the onset dominant frequency was compared to the dominant frequency at the end of the sound. The harmonics showed the same pattern. Overall, the buzzing sounds had a mean SPL of 106.4 dB re $1 \mu \mathrm{Pa}$ rms (range 92.1-119.3 dB re $1 \mathrm{~Pa}$ rms), and could be as long as $1600 \mathrm{~ms}$ (mean $=230 \pm$ $187.5 \mathrm{~ms}$; Table 2).
The 3 soft lobsters tested during the feeding experiments were also observed to be capable of emitting buzzing sounds, and more frequently than the intermolt lobsters. We observed no significant differences in buzzing sounds emitted between postmolt and intermolt lobsters in the sound duration, SPL and peak frequencies (MW, $p>0.05$ ). However, the bandwidth was significantly larger for intermolt lobsters compared to postmolt lobsters (MW, p < 0.05). In addition, one postmolt lobster (12 cm CL) emitted 3 buzzing sounds with the highest SPL (>119 dB re $1 \mu \mathrm{Pa}$ rms) values observed here.

\section{DISCUSSION}

\section{Quantification of bioacoustic signatures in tanks}

Characterizing reverberation in the different tanks required using known sound in order to be able to quantify how the tank geometry distorted sounds. As expected, reverberation distorted the white noise used in our tests for all the tanks. Several peak frequencies appeared corresponding to the calculated theoretical resonant frequencies of the different tanks (Table 1). The same result was also found for recordings of broadband rattles emitted by the lobsters in these tanks (Fig. 1). Based on these observations, and inspired by Akamatsu et al. (2002), we summarized these results as a guideline for charac- 
terizing marine crustaceans' sounds in small tanks (Table 3).

Although we recognize that this information exists in various forms in the acoustic literature, it seems important to present these guidelines directly to the bioacoustic community, where studies of crustaceans in tanks are frequently described in the literature (Hazlett \& Winn 1962a,b, Meyer-Rochow \& Penrose 1974, 1976, Mulligan \& Fischer 1977, Patek \& Caldwell 2006, Patek \& Baio 2007, Patek et al. 2009, Buscaino et al. 2011, 2015, Coquereau et al. 2016a,b). Most of these studies did not attempt to quantify reverberation effects on the broadband and transient sounds. For example, Meyer-Rochow \& Penrose (1976) found that spectral characteristics of the squeak produced by the rock lobster Palinurus longipes were strongly influenced by the size and material of their recording tanks, and finally concluded that the bandwidth was uniform over the audio range. Different types of sound characteristics are commonly presented in the bioacoustic literature, including: spectral characteristics (peak frequencies, bandwidth), time (duration, pulse rate, time interpulse) and measured energy (SPL) and source energy ((SL; i.e. SPL estimated at one distance from a source)). In our study, we have shown that spectral characteristics in transient and broadband sounds (such as rattles), which are usually produced by crustaceans, cannot be calculated in tanks.

In contrast, low-frequency sounds (such as buzzing) can be measured in tanks. Yet other analytical methods based on SPL, such as SL estimated at $1 \mathrm{~m}$ from a source, do not appear reliable because of the sound

Table 3. Acoustic methodology showing which sound characteristics (spectral, time, energy) can be calculated in small tanks (example: $0.105 \mathrm{~m}^{3}$ ) depending on the type of recorded sound. The sound characteristics were calculated selecting the entire sound. $f_{\text {res }}$ : minimum resonant frequency of the tank; SPL: sound pressure level; SL: source energy (i.e. SPL estimated at one distance from a source)

\begin{tabular}{|c|c|c|}
\hline \multirow{2}{*}{$\begin{array}{l}\text { Sound } \\
\text { characteristic }\end{array}$} & \multicolumn{2}{|c|}{ Sound frequency } \\
\hline & $<f_{\text {res }}$ & $>f_{\text {res }}$ \\
\hline Spectral shape & Ok & No \\
\hline Time (duration) & Ok & No \\
\hline $\begin{array}{l}\text { Time (beginning } \\
\text { of the sound) }\end{array}$ & Ok & $\begin{array}{l}\text { Ok (if sound is } \\
\text { separated enough } \\
\text { from other sound) }\end{array}$ \\
\hline SPL & Ok & Possible if $f>>f_{\text {res }}$ \\
\hline SL & No & Possible if $f>>f_{\text {res }}$ \\
\hline $\begin{array}{l}\text { Examples from } \\
\text { this study }\end{array}$ & $\begin{array}{c}\text { Buzzing } \\
\text { (narrowband and } \\
\text { continuous sounds) }\end{array}$ & $\begin{array}{c}\text { Rattles } \\
\text { (broadband and } \\
\text { transient sounds) }\end{array}$ \\
\hline
\end{tabular}

propagation models in use. As a reminder, Rogers et al. (2016) investigated transmission loss in the same range as our buzzing sounds in very small $\left(0.03 \mathrm{~m}^{3}\right)$ tanks. They showed an exponential decrease of $35 \mathrm{~dB}$ between 10 and $30 \mathrm{~cm}$ from the hydrophone, whereas based on the spherical spreading propagation model commonly used, the expected transmission loss would be estimated at only $10 \mathrm{~dB}$. These results suggest that the SL values would also be unreliable in our experiments (Table 3). One solution to infer crustacean SLs in tank experiments would be to develop new propagation models, such as the one proposed by Rogers et al. (2016). This would require very accurate estimations of the source position, which is unfortunately not possible at this time for crustaceans because they are allowed to move freely in the tanks and thus cannot be considered as a fixed-point source.

\section{Comparison with the bioacoustic literature}

Rattles emitted by Homarus gammarus during feeding were defined as trains of broadband pulses. In the present study, first peak frequency, bandwidth and SPL were not assessed because the recordings were highly distorted due to reverberation (Table 1, Fig. 1). Other authors have suggested that broadband and transient sounds emitted by marine arthropods can be characterized by sampling only the initial part of the signal (e.g. an interval less than $0.2 \mathrm{~ms}$ ), which would correspond to a 1-way emission just before reverberation starts (Coquereau et al. 2016a). This method was not applied in the present study, because it would not determine whether the frequencies of transient sounds vary over time. For example, beaked whales emit sounds with very fast frequency modulations (Baumann-Pickering et al. 2013), which this type of signal sub-sampling would not account for. In addition, calculating a power spectral density with too few points may not fulfill the conditions for accurately estimating spectral characteristics. Thus, we preferred to focus on descriptors not impacted by tank reverberation, such as time characteristics: the duration of the entire sound, pulse-to-pulse time interval, number of pulses per train, and pulse rate.

The time characteristics of the lobsters' rattles were consistent with the feeding sounds previously reported for tropical spiny lobsters. The mean entire duration of $223 \mathrm{~ms}$ was of the same order of magnitude (Moulton 1957: $250 \mathrm{~ms}$ for Palinurus argus; Meyer-Rochow \& Penrose 1976: 153 ms for P. longipes). Other types of feeding sounds recorded in 
temperate crustaceans had longer durations (Coquereau et al. 2016a: approximately $600 \mathrm{~ms}$ for Maja brachydactyla; Coquereau et al. 2016b: approximately $400 \mathrm{~ms}$ for Cancer pagurus). The number of pulses per signal was calculated as (mean \pm SD) $12 \pm 7.8$ on average for lobster rattles, which compares favourably with the reported 5 to 10 pulses per signal for spiny lobsters (Moulton 1957 for P. argus; Meyer-Rochow \& Penrose 1976 for $P$. longipes), but is smaller than the mean of $29 \pm 11$ pulses per signal reported for $M$. brachydactyla (Coquereau et al. 2016a). In a general way, time characteristics in lobsters' rattles were highly variable. These rattles may be produced by the friction between mouthparts (called 'mandible grinding' in Meyer-Rochow \& Penrose 1976), suggesting unintentional sounds are produced and may thus account for some of this reported variability.

Similar to the American lobster, the European lobster also produces a buzzing sound (Henninger \& Watson 2005) that could be recorded by the hydrophone (Fig. 2). First peak frequencies in the European lobster were within the range of reported first peak frequencies by Fish (1966; 100 to $130 \mathrm{~Hz}$ ) and Henninger \& Watson $(2005 ; 87$ to $261 \mathrm{~Hz})$ for the American lobster. Sound durations, however, were highly variable (50 to $1600 \mathrm{~ms}$ ), but were in the same range as those reported by both Fish (1966; between 100 and $500 \mathrm{~ms}$ ) and Henninger \& Watson (2005; between 68 to $1720 \mathrm{~ms}$ ). In addition, the mean SPL was estimated to be about $10 \mathrm{~dB}$ re $1 \mu \mathrm{Pa}$ rms lower than for American lobsters (between 116.5 and $118.5 \mathrm{~dB}$ re $1 \mu \mathrm{Pa}$ rms; Fish 1966, Henninger \& Watson 2005, Ward et al. 2011). A second strong harmonic was also observed in the European lobster that has not been described for the American lobster. The bandwidth showed how the buzzing sound decreased in frequency over time, suggesting that these types of modulations may be a characteristic of this sound. Similar results have indeed already been reported from stomatopods or mantis shrimp Hemisquilla californiensis, which generate tonal, low frequency sounds called 'rumbles' (Patek \& Caldwell 2006). These same authors also observed that the first peak frequencies of the rumbles were accompanied with a second strong harmonic. Staaterman et al. (2011) reported 'rumbles' recorded in the field close to our results for lobsters buzzing sounds (an average dominant frequency of $167 \mathrm{~Hz}$ and a mean duration of $200 \mathrm{~ms}$ ). Apart from these 3 marine crustacean species, a number of other marine organisms also generate similar low frequency sounds, including whales and fish (Clark \& Johnson 1984, Connaughton 2004, Maruska \& Mensinger 2009).

\section{Is there a role for buzzing sounds emitted by the European lobster?}

Because of the lack of field observations in the ecological context in which buzzing sounds are generated, it is only possible to speculate about their role based on comparisons with other organisms. As lobsters produced vibrations when handled (this was already demonstrated in Henninger \& Watson 2005), it has been suggested that buzzing sounds may serve to deter potential predators. These sounds have a narrow bandwidth, suggesting that only organisms capable of perceiving sounds in the same band of frequencies might be targeted. Ward et al. (2011) showed that American lobsters vibrated when approached by 2 species of fish in a circular tank (cod and striped bass). Interestingly, the sound sensitivity of cephalopods, including octopuses, seems to be limited to low frequencies (100-200 Hz; Williamson 1988, Packard et al. 1990, Mooney et al. 2010). As the octopus is a well-known predator of European lobsters (Barshaw et al. 2003), these buzzing sounds may indeed be meant as a deterrence.

Buzzing sounds were also recorded just before 2 male lobsters attacked the hydrophone during feeding experiments. Lobsters are known to be territorial species living in burrows similar to those of mantis shrimp (Dingle \& Caldwell 1969), and buzzing sounds might help to send signals of their presence to conspecifics in addition to chemical cues (Skog et al. 2009), to maintain territory. This type of behaviour was previously described in mantis shrimp (Patek \& Caldwell 2006). Staaterman et al. (2011) recorded multiple rumbles of mantis shrimp in the field, which they termed 'chorusing'. These rhythmic series, called 'rumble groups', may even constitute a type of conspecific communication.

Crustaceans, including lobsters, lack gas-filled organs (i.e. swim bladders) required for pressure detection, but may be still capable of detecting lowfrequency acoustic stimuli arising from particle motion (Popper et al. 2001, Edmonds et al. 2016, Popper \& Hawkins 2018), such as the buzzing sounds. A large diversity of sensory receptors has been described in crustaceans, including statocysts and sensory hairs (Popper et al. 2001, Radford et al. 2016). Two types of putative acoustic receptors on $H$. gammarus-hairfan and hair-peg organs - have been implicated in low-frequency sound and water-current detection (Laverack 1962, 1963). In addition, one study focused on sound detection by $H$. americanus showed that they are capable of detecting sounds, with the most sensitive responses at the lower frequencies (be- 
tween 18.7 and $150 \mathrm{~Hz}$; Offutt 1970). Our results also showed that 'soft' (postmolt) lobsters were able to produce buzzing sounds with the same characteristics (except for their bandwidth) as 'hard' (intermolt) lobsters. This suggests that the buzzing sounds may be a means of communication. New studies are needed to clearly examine the physiological and behavioural responses of European lobsters to such sounds.

Henninger \& Watson (2005) showed that only 7.5\% of their American lobsters (from a total of 1723 individuals tested) vibrated when handled, despite the fact that all lobsters have the anatomical capacity to produce these sounds. Their year-long survey demonstrated that all size classes of American lobster can produce buzzing sounds, with a similar distribution for both males and females. In the present study, we observed that only 7 out of the 17 lobsters tested vibrated and produced buzzing sounds when handled. We recorded buzzing sounds in 6 male and only 1 female lobster, meaning that 1 male and 9 female lobsters did not vibrate. Due to the low number of individuals tested, and to the stress of captivity, which could habituate lobsters to being disturbed, we cannot yet explain this difference in sound production between individuals. Further, we do not know at which stage of their life cycle the mechanism of sound production becomes operational and biologically useful in these animals.

\section{Conclusions}

Passive acoustic studies of marine crustaceans would clearly benefit from field measurements. Indeed, we emphasize that field studies are required to confirm the acoustic findings presented in this study and to test hypotheses about sound transmission and detection in natural soundscape. Preliminary characterization of European lobsters' buzzing sounds, however, suggests these could be difficult to record because they may be masked by other sources of low-frequency sounds, such as sea surface agitation related to wind speed (Wenz 1962) and anthropogenic noise (Clark et al. 2009). In conclusion, acoustic measurements in carefully controlled laboratory conditions together with behavioural observations remain an essential first step, and they should serve as a basis of comparison for any subsequent in situ research and monitoring projects.

Acknowledgements. We thank the aquariology staff of the public aquarium Océanopolis in Brest (France) for their technical support. We also thank the 2 anonymous referees for comments on the manuscript. J.C.G.'s contribution was supported by the 'Laboratoire d'Excellence' LabexMER (ANR-10-LABX-19) and co-funded by a grant from the French government under the program 'Investissements d'Avenir'. J.B.'s contribution was supported by ENSTA Bretagne (France) and by the Investment in Science Fund at WHO (USA). This project was funded by Benthoscope.

\section{LITERATURE CITED}

Agnalt AL, Kristiansen TS, Jørstad KE (2007) Growth, reproductive cycle, and movement of berried European lobsters (Homarus gammarus) in a local stock off southwestern Norway. ICES J Mar Sci 64:288-297

Akamatsu T, Okumura T, Novarini N, Yan HY (2002) Empirical refinements applicable to the recording of fish sounds in small tanks. J Acoust Soc Am 112:3073-3082

Au WWL, Banks K (1998) The acoustics of the snapping shrimp Synalpheus parneomeris in Kaneohe Bay. J Acoust Soc Am 103:41-47

Audacity Team (2015) Audacity® version 2.1.1. www. audacityteam.org

* Barshaw DE, Lavalli KL, Spanier E (2003) Offense versus defense: responses of three morphological types of lobsters to predation. Mar Ecol Prog Ser 256:171-182

* Baumann-Pickering S, McDonald MA, Simonis AE, Solsona Berga A, and others (2013) Species-specific beaked whale echolocation signals. J Acoust Soc Am 134: 2293-2301

* Boon PY, Yeo DCJ, Todd PA (2009) Sound production and reception in mangrove crabs Perisesarma spp. (Brachyura: Sesarmidae). Aquat Biol 5:107-116

* Bouwma PE, Herrnkind WF (2009) Sound production in Caribbean spiny lobster Panulirus argus and its role in escape during predatory attack by Octopus briareus. N Z J Mar Freshw Res 43:3-13

* Buscaino G, Filiciotto F, Gristina M, Bellante A and others (2011) Acoustic behaviour of the European spiny lobster Palinurus elephas. Mar Ecol Prog Ser 441:177-184

* Buscaino G, Gavio MA, Galvan DE, Filiciotto F, and others (2015) Acoustic signals and behaviour of Ovalipes trimaculatus in the context of reproduction. Aquat Biol 24: 61-73

Clark CW, Johnson JH (1984) The sounds of the bowhead whale, Balaena mysticetus, during the spring migrations of 1979 and 1980. Can J Zool 62:1436-1441

* Clark CW, Ellison WT, Southall BL, Hatch L and others (2009) Acoustic masking in marine ecosystems: intuitions, analysis, and implication. Mar Ecol Prog Ser 395: 201-222

Cobb JS, Wahle R (1994) Early life history and recruitment processes of clawed lobsters. Crustaceana 67:1-25

Connaughton MA (2004) Sound generation in the searobin (Prionotus carolinus), a fish with alternate sonic muscle contraction. J Exp Biol 207:1643-1654

Coquereau L, Grall J, Chauvaud L, Gervaise C, Clavier J, Jolivet A, Di Iorio L (2016a) Sound production and associated behaviours of benthic invertebrates from a coastal habitat in the north-east Atlantic. Mar Biol 163:127

* Coquereau L, Grall J, Clavier J, Jolivet A, Chauvaud L (2016b) Acoustic behaviours of large crustaceans in NE Atlantic coastal habitats. Aquat Biol 25:151-163

* Dingle H, Caldwell RL (1969) The aggressive and territorial behaviour of the mantis shrimp Gonodactylus bredini Manning (Crustacea: Stomatopoda). Behaviour 33: $115-136$ 
Duncan AJ, Lucke K, Erbe C, McCauley RD (2016) Issues associated with sound exposure experiments in tanks. Proc Meet Acoust 27:070008

Edmonds NJ, Firmin CJ, Goldsmith D, Faulkner RC, Wood DT (2016) A review of crustacean sensitivity to high amplitude underwater noise: data needs for effective risk assessment in relation to UK commercial species. Mar Pollut Bull 108:5-11

Erbe C (2010) Underwater acoustics: noise and the effects on marine mammals. JASCO Applied Sciences, Brisbane

F Fish JF (1966) Sound production in the American lobster, Homarus americanus H. Milne Edwards (Decapoda Reptantia). Crustaceana 11:105-106

* Guinot-Dumortier D, Dumortier B (1960) La stridulation chez les crabes. Crustaceana 1:117-155

Hazlett BA, Winn HE (1962a) Sound production and associated behavior of Bermuda crustaceans (Panulirus, Gonodactylus, Alpheus, and Synalpheus). Crustaceana $4: 25-38$

Hazlett BA, Winn HE (1962b) Characteristics of a sound produced by the lobster Justitia longimanus. Ecology 43: 741-742

Henninger HP, Watson WH (2005) Mechanisms underlying the production of carapace vibrations and associated waterborne sounds in the American lobster, Homarus americanus. J Exp Biol 208:3421-3429

Holthuis LB (1991) Marine lobsters of the world. An annotated and illustrated catalogue of species of interest to fisheries known to date. FAO Species Catalogue, Vol. 13, FAO, Rome

Knowlton RE, Moulton JM (1963) Sounds production in the snapping shrimps Alpheus (Crangon) and Synalpheus. Biol Bull 125:311-331

Laverack MS (1962) Responses of cuticular sense organs of the lobster, Homarus vulgaris (Crustacea)-II. Hair-fan organs as pressure receptors. Comp Biochem Physiol 6: $137-145$

Laverack MS (1963) Responses of cuticular sense organs of the lobster, Homarus vulgaris (Crustacea) - III. Activity invoked in sense organs of the carapace. Comp Biochem Physiol 10:261-272

Maruska KP, Mensinger AF (2009) Acoustic characteristics and variations in grunt vocalizations in the oyster toadfish Opsanus tau. Environ Biol Fishes 84:325-337

Mendelson M (1969) Electrical and mechanical characteristics of a very fast lobster muscle. J Cell Biol 42:548-563

Meyer-Rochow VB, Penrose JD (1974) Sound and sound emission apparatus in puerulus and postpuerulus of the western rock lobster (Panulirus longipes). J Exp Zool 189:283-289

* Meyer-Rochow VB, Penrose JD (1976) Sound production by the western rock lobster Panulirus longipes (Milne Edwards). J Exp Mar Biol Ecol 23:191-209

Mooney TA, Hanlon RT, Christensen-Dalsgaard J, Madsen PT, Ketten DR, Nachtigall PE (2010) Sound detection by the longfin squid (Loligo pealeii) studied with auditory evoked potentials: sensitivity to low-frequency particle motion and not pressure. J Exp Biol 213:3748-3759

Moulton JM (1957) Sound production in the spiny lobster Panulirus argus (Latreille). Biol Bull 113:286-295

Mulligan BE, Fischer RB (1977) Sounds and behavior of the spiny lobster Panulirus argus (Latreille, 1804) (Decapoda, Palinuridae). Crustaceana 32:185-199

Offutt GC (1970) Acoustic stimulus perception by the American lobster Homarus americanus (Decapoda). Experientia 26:1276-1278

Editorial responsibility: Victor Benno Meyer-Rochow, Oulu, Finland
Packard A, Karlsen HE, Sand O (1990) Low frequency hearing in cephalopods. J Comp Physiol A 166:501-505

Parvulescu A (1964) Problems of propagation and processing. In: Tavolga WN (ed) Marine bioacoustics. Pergamon Press, Oxford, p 87-100

Parvulescu A (1967) The acoustics of small tanks. In: Tavolga WN (ed) Marine bioacoustics. Pergamon Press, Oxford, p 7-13

* Patek SN (2001) Spiny lobsters stick and slip to make sound. Nature 411:153-154

Patek SN, Baio J (2007) The acoustic mechanics of stick-slip friction in the California spiny lobster (Panulirus interruptus). J Exp Biol 210:3538-3546

Patek SN, Caldwell RL (2006) The stomatopod rumble: low frequency sound production in Hemisquilla californiensis. Mar Freshwat Behav Physiol 39:99-111

Patek SN, Shipp LE, Staaterman ER (2009) The acoustics and acoustic behavior of the California spiny lobster (Panulirus interruptus). J Acoust Soc Am 125:3434-3443

Pierce AD (1981) Acoustics. McGraw-Hill, New York, NY

*Popper AN, Hawkins AD (2018) The importance of particle motion to fishes and invertebrates. J Acoust Soc Am 143: 470-488

Popper AN, Salmon M, Horch KW (2001) Acoustic detection and communication by decapod crustaceans. J Comp Physiol A 187:83-89

Radford CA, Tay K, Goeritz ML (2016) Hearing in the paddle crab, Ovalipes catharus. Proc Meet Acoust 27:010013

Rogers PH, Hawkins AD, Popper AN, Fay RR, Gray MD (2016) Parvulescu revisited: small tank acoustics for bioacousticians. In: The effects of noise on aquatic life II. Springer, New York, NY, p 933-941

* Schroeder MR (1996) The 'Schroeder frequency' revisited. J Acoust Soc Am 99:3240-3241

Sheehy MRJ, Bannister RCA, Wickins JF, Shelton PMJ (1999) New perspectives on the growth and longevity of the European lobster (Homarus gammarus). Can J Fish Aquat Sci 56:1904-1915

Skog M, Chandrapavan A, Hallberg E, Breithaupt T (2009) Maintenance of dominance is mediated by urinary chemical signals in male European lobsters, Homarus gammarus. Mar Freshwat Behav Physiol 42:119-133

Smith IP, Collins KJ, Jensen AC (1998) Movement and activity patterns of the European lobster, Homarus gammarus, revealed by electromagnetic telemetry. Mar Biol 132:611-623

* Staaterman ER, Clark CW, Gallagher AJ, de Vries MS, Claverie T, Patek SN (2011) Rumbling in the benthos: acoustic ecology of the California mantis shrimp Hemisquilla californiensis. Aquat Biol 13:97-105

Tyack PL, Clark CW (2000) Communication and acoustic behavior of dolphins and whales. In: Au WWL, Popper AN, Fay RR (eds) Hearing by whales and dolphins. Springer, New York, NY, p 156-224

* Versluis M, Schmitz B, von der Heydt A, Lohse D (2000) How snapping shrimp snap: through cavitating bubbles. Science 289:2114-2117

* Ward D, Morison F, Morrissey E, Jenks K, Watson WH (2011) Evidence that potential fish predators elicit the production of carapace vibrations by the American lobster. J Exp Biol 214:2641-2648

*Wenz GM (1962) Acoustic ambient noise in ocean spectra and sources. J Acoust Soc Am 34:1936-1956

Williamson R (1988) Vibration sensitivity in the statocyst of the northern octopus, Eledone cirrosa. J Exp Biol 134: 451-454

Submitted: December 6, 2017; Accepted: March 9, 2018

Proofs received from author(s): April 23, 2018 